East African Medical Journal Vol. 87 No. 5 May 2010

CARDIOTOCOGRAPHY AND PERINATAL OUTCOME IN WOMEN WITH AND WITHOUT MECONIUMSTAINED LIQUOR

B. E. Odongo, MBChB, MMed (Obs/Gynae), P.O. Box 4-00202, Nairobi, Kenya, P. M. Ndavi, MBChB, MMed (Obs/ Gynae), MPH, Associate Professor, O.W. Gachuno, MBChB, MMed (Obs/ Gynae), Lecturer, Department of Obstetrics and Gynaecology, College of Health Sciences, University of Nairobi, P. O. Box 19714-00202, Nairobi, Kenya and E. Sequeira, Senior Lecturer, Department of Obstetrics and Gynaecology, Aga Khan University Hospital, Nairobi, P.O. Box 30270-00100, Nairobi, Kenya

Request for reprints to: Dr. B. E. Odongo, P.O. Box 4-00202, Nairobi, Kenya

\title{
CARDIOTOCOGRAPHY AND PERINATAL OUTCOME IN WOMEN WITH AND WITHOUT MECONIUM STAINED LIQUOR
}

\author{
B. E. ODONGO, P. M. NDAVI, O.W. GACHUNO and E. SEQUEIRA
}

\begin{abstract}
Background: There is little evidence linking meconium stained liquor to poor perinatal outcome and clear amniotic fluid is frequently considered a reassuring sign during labour.

Objective: To determine whether there are any differences in cardiotocography (CTG) tracings and perinatal outcomes in women with meconium stained compared with those with clear liquor in labour.

Design: A prospective cohort study.

Setting: The Aga Khan University Hospital, Nairobi.

Subjects: Seventy seven women presenting in labour were studied. Thirty six had meconium stained liquor and 41 had clear liquor.

Main outcome measures: Initial and intrapartum CTG was done. Perinatal and maternal outcomes determined were birth weights, Apgar scores, admission due to foetal indications and puerperal sepsis. CTG interpretation was based on RCOG/NICE guidelines-2001. SPSS 12.0.1 was used for all analyses.

Results: Variable decelerations were the most common foetal heart rate patterns. In the initial CTG, suspicious (RR 1.033,95\% CI: 0.515 - 2.073), and pathologic (RR 1.490, 95\% CI: 0.928-2.393) patterns were increased in the meconium stained group. In the intrapartum CTG, pathologic pattern was increased in women with meconium stain liquor (RR 1.096, 95\% CI: 0.650-1.847). Apgar score of $<7$ was likely if the initial base line rate was abnormal (RR 1.357,95\% CI: 0.139-1.009, irrespective of the state of liquor. Meconium staining of liquor was associated with Caesarean delivery $(R R=1.357,95 \%$ CI: 1.010-1.823; P-value 0.042). There was no significant difference in the mean birth weights of the infants born to women in both groups ( 3359.72 grams and 3260.24 grams respectively, $\mathrm{P}=\mathbf{0 . 2 8 2}$ ). One minute Apgar score in both groups was not significantly (RR 0.390,95\% CI:0.131-1.1611).

Conclusion: The suspicious and pathologic tracings were increased in the meconium stained liquor group. There was no significant difference in the Apgar scores in both groups of women. Meconium staining of liquor was significantly associated with Caesarean delivery.
\end{abstract}

\section{INTRODUCTION}

Meconium staining of amniotic fluid occurs in about $12-14 \%$ of all pregnancies and could be a potential warning sign of asphyxia (1-3). The significance of meconium-stained amniotic fluid as a sign of foetal distress remains controversial and its reliability as a predictor of foetal compromise has been questioned $(1,2)$. However its presence remains a concern to both obstetricians and neonatologists since signs of asphyxia and meconium staining are associated with an increase in perinatal morbidity and mortality (1). Clear amniotic fluid is frequently considered a reassuring sign during labour but its presence is an unreliable sign of foetal well being (2). In the absence of CTG, clinicians rely on the colour of meconium and intrapartum foetal auscultation to identify foetal distress. 


\section{MATERIALS AND METHODS}

Study area: The study was carried out at The Aga Khan University Hospital, Nairobi which is a 254-bed tertiary care facility and a teaching hospital for post graduate medical students and advanced nursing programmes.

Study design: A prospective cohort study of 77 women presenting in labour, 36 had meconium stained liquor and 41 had clear liquor.

Study period: The study began in August 2006 until January 2007 when the sample size was attained.

Clinical methods: Once a woman met the eligibility criteria a vaginal examination was performed. If labour was established and the cervix found to be favourable with intact membranes, artificial rupture of membranes was done. The women with spontaneous rupture of membranes at term were also enrolled into the study.

In those women with clear liquor and grade 1 staining of amniotic fluid, an initial 30 minutes CTG was done and subsequent CTG was done intermittently.

In those women with meconium stained liquor grade 2 in active labour, continuous CTG was maintained. In those with reassuring pattern, vaginal delivery was planned but those with non reassuring pattern, resuscitative measures e.g. rehydration, repositioning of the woman, oxygen administration and stoppage of oxytocin administration were done. However if a non reassuring pattern persisted or the tracings became pathologic, delivery was by emergency Caesarean section.

In those women who had grade 2 meconium in early labour (i.e. less than $3 \mathrm{~cm}$ dilatation) and those with grade 3 meconium in latent or active phases of labour (except 2 nd stage), delivery was expedited by emergency Caesarean section. However they were on continuous CTG monitor to the point of being wheeled to theatre.

The CTG tracings interpretation was based on RCOG/NICE guidelines-2001 (Adopted by FIGO) (5). On a sample of tracings, a re-evaluation of intra observer and interobserver agreement between two different obstetricians was conducted to confirm reliability of interpretations.

A follow-up of perinatal and maternal outcomes was performed which included Apgar scores, admission to intensive care unit or delayed discharge due to foetal indications and puerperal sepsis. The women were reviewed for signs of sepsis one week after discharge.

Data analysis and presentation:SPSS 12.0.1 was used for all analyses. A comparison between the two groups was performed with chi-square test (or Fisher's exact test, when appropriate) for categorical variables and student t-test for continuous variables with normal distribution. A probability value of $<0.05$ was considered statistically significant. Relative risk and their 95\% CIs were calculated.

\section{RESULTS}

There was no significant difference in the duration of time from onset of labour to admission $(p=0.185)$ and in cervical dilatation at admission $(p=1.000)$. Parturients with clear liquor had a longer mean duration of labour (11.44hours compared with 9.92hoursin the meconium group) though this was not statistically significant $(p=0.07)$.Those with clear liquor had statistically significant higher rates of augmentation of labour by oxytocin ( $p=0.003)$ (Table 1$)$.

Table 1

Labour characteristics of the participants

\begin{tabular}{|c|c|c|c|}
\hline Characteristic & Clear $(\mathrm{n}=41)$ & Meconium $(n=36)$ & P-value (0.05) \\
\hline \multicolumn{4}{|l|}{ Onset of labour pains (hours) } \\
\hline$<4$ & $21(51.2 \%)$ & $12(33.3 \%)$ & \\
\hline $4-8$ & $8(19.5 \%)$ & $13(36.1 \%)$ & 0.185 \\
\hline$>8$ & $12(29.3 \%)$ & $11(30.6 \%)$ & \\
\hline \multicolumn{4}{|l|}{ Cervical dilatation $(\mathrm{cm})$} \\
\hline$<3$ & $20(48.8 \%)$ & $17(47.2 \%)$ & $\begin{array}{l}1.000 \\
\text { (Fisher's exact) }\end{array}$ \\
\hline $4-9$ & $21(52.2 \%)$ & $19(52.8 \%)$ & \\
\hline Duration of labour in hours (mean) & 11.44 & 9.92 & 0.070 \\
\hline \multicolumn{4}{|l|}{ Syntocinon use } \\
\hline Yes & $35(64.8 \%)$ & $19(52.8 \%)$ & $\begin{array}{l}0.003 \\
\text { (Fisher's exact) }\end{array}$ \\
\hline No & $6(26.1 \%)$ & $17(47.2 \%)$ & \\
\hline
\end{tabular}


Variable decelerations were the most common abnormal foetal heart rate patterns observed at admission and also intrapartum in both groups.

In the initial CTG tracings, $41 \%$ of the clear liquor group had variable decelerations compared with $36.1 \%$ in the meconium stained liquor group.

In the intrapartum CTG tracings, $29.3 \%$ in the clear liquor group had variable decelerations compared with $27.8 \%$ in meconium stained liquor group. One sinusoidal pattern was described in the meconium stained liquor group (Table 2).
IninitialCTG, the relative risk of having suspicious (RR 1.033, 95\% CI: 0.515 - 2.073), and pathologic (RR 1.490,95\% CI:0.928-2.393) CTG patterns wasincreased in the meconium stained liquor group compared with the clear liquor group. However a significant percentage of suspicious (14.6\%) pathologic $(65.9 \%)$ was seen in the clear liquor group (Table 3).

This was also observed in the intrapartum CTG whereby the relative risk of having a pathologic CTG with meconium stain was increased (RR 1.096, 95\% CI; 0.650-1.847). Pathologic pattern was present in $(75.6 \%)$ of women with clear liquor (Table 3).

Table 2

Frequencies of specific foetal heart rate patterns recorded on the CTG tracings

\begin{tabular}{|c|c|c|c|c|c|c|c|c|}
\hline \multirow{3}{*}{ Characteristic } & \multicolumn{4}{|c|}{ Initial CTG } & \multicolumn{4}{|c|}{ Intrapartum CTG } \\
\hline & \multicolumn{2}{|c|}{ Clear $(\mathrm{n}=41)$} & \multicolumn{2}{|c|}{ Meconium $(\mathrm{n}=36)$} & \multicolumn{2}{|c|}{ Clear $(\mathrm{n}=41)$} & \multicolumn{2}{|c|}{ Meconium $(\mathrm{n}=36)$} \\
\hline & No. & $(\%)$ & No. & $(\%)$ & No & $(\%)$ & No. & $(\%)$ \\
\hline \multicolumn{9}{|l|}{ Baseline rate } \\
\hline Normal & 36 & 87.8 & 33 & 91.7 & 38 & 92.7 & 32 & 88.9 \\
\hline Abnormal & 5 & 12.2 & 3 & 8.3 & 3 & 7.3 & 4 & 11.1 \\
\hline \multicolumn{9}{|l|}{ Baseline rate variability } \\
\hline Normal & 39 & 95.1 & 35 & 97.2 & 40 & 97.6 & 33 & 91.7 \\
\hline Non reassuring & 1 & 2.4 & 1 & 2.8 & 0 & 0 & 1 & 2.8 \\
\hline Abnormal & 1 & 2.4 & 0 & 0 & 1 & 2.4 & 2 & 5.6 \\
\hline \multicolumn{9}{|l|}{ Decelerations } \\
\hline Early & 14 & 34.1 & 19 & 52.8 & 16 & 39 & 14 & 38.9 \\
\hline Variable & 17 & 41 & 13 & 36.1 & 12 & 29.3 & 10 & 27.8 \\
\hline Atypical variable & 0 & 0 & 1 & 2.8 & 5 & 12.2 & 4 & 11.1 \\
\hline Late & 5 & 12.2 & 2 & 5.6 & 4 & 9.8 & 5 & 13.8 \\
\hline Sinusoidal pattern & 0 & 0 & 1 & 2.8 & 0 & 0 & 1 & 2.8 \\
\hline None & 5 & 12.2 & 0 & 0 & 4 & 9.8 & 2 & 5.6 \\
\hline
\end{tabular}

Table 3

Normal, suspicious and pathologic tracings

\begin{tabular}{|c|c|c|c|c|c|c|c|}
\hline \multirow{3}{*}{\multicolumn{2}{|c|}{ Characteristic }} & \multicolumn{5}{|c|}{ Meconium stained Clear liquor } & \multirow[t]{3}{*}{$(95 \% \mathrm{CI})$} \\
\hline & & Liqu & lor $(n=36)$ & $(\mathrm{n}=$ & & $\mathrm{RR}$ & \\
\hline & & No. & $(\%)$ & No. & $(\%)$ & & \\
\hline \multirow[t]{3}{*}{ Initial CTG } & Normal & 14 & 38.9 & 8 & 19.5 & & \\
\hline & Suspicious & 5 & 13.9 & 6 & 14.6 & 1.033 & $0.515-2.073$ \\
\hline & Pathologic & 17 & 47.2 & 27 & 65.9 & 1.490 & $0.928-2.393$ \\
\hline \multicolumn{8}{|c|}{ Intra- partum CTG } \\
\hline & Normal & 10 & 27.8 & 10 & 24.4 & 0.919 & $0.558-1.514$ \\
\hline & Pathologic & 26 & 72.2 & 31 & 75.6 & 1.096 & $0.650-1.847$ \\
\hline
\end{tabular}


There was no significant difference in the mean birth weights of the infants born to mothers with clear liquor compared to those with meconium stained liquor (3260.24 grams and 3359.72 grams respectively, $\mathrm{p}=0.282$ ). Meconium staining of liquor was significantly associated with Caesarean section delivery $(\mathrm{RR}=1.357,95 \% \mathrm{CI}$ : 1.010-1.823; p value 0.042) (Table 4). Caesarean section delivery occurred in seven $(17.1 \%)$ of the clear liquor group compared with $14(38.9 \%)$ in the meconium stained liquor group. (Table 4).

The risk of having a poor Apgar score in the clear liquor group compared with the meconium group was not significant (RR 0.390, 95\% CI: 0.131-1.160). However the clear liquor group were more likely to have a good Apgar score at 1 minute compared with the meconium group(RR 1.203,95\% CI: 0.972-1.490). At 5 minutes only one neonate (who was in the clear liquor group) had an Apgar score of $<7$.This value did not allow statistical modeling. The rest had a 5 minute Apgar score of more than 7 (Table 5).

In the initial CTG, the relative risk of having an Apgar score of $<7$ was more likely if the initial base line rate was abnormal (RR 1.357,95\% CI: 0.139-1.009) (Table 6).

Table 4

Foetal outcomes

\begin{tabular}{lllll}
\hline & $\begin{array}{l}\text { Meconium stained } \\
\text { liquor }(\mathrm{n}=36)\end{array}$ & $\begin{array}{l}\text { Clear liquor } \\
(\mathrm{n}=41)\end{array}$ & RR & $95 \%$ CI \\
\hline $\begin{array}{l}\text { Delivery mode } \\
\text { Caesarean section }\end{array}$ & $14(38.9 \%)$ & $7(17.1 \%)$ & 1.357 & $1.010-1.823$ \\
SVD & $22(61.1 \%)$ & $34(82.9 \%)$ & 0.439 & $0.199-0.967$ \\
Mean birth weight (grams) 3359.72 & 3260.24 & P-value 0.282 & \\
\hline
\end{tabular}

Table 5

Apgar scores at 1 minute

\begin{tabular}{|c|c|c|c|c|c|}
\hline & \multicolumn{2}{|c|}{ Clear liquor $(n=41)$} & \multirow{2}{*}{$\begin{array}{l}\text { Meconium stained } \\
\text { liquor }(\mathrm{n}=36) \\
\text { No. }(\%)\end{array}$} & \multirow[t]{2}{*}{ RR } & \multirow[t]{2}{*}{$95 \% \mathrm{CI}$} \\
\hline & No. & $(\%)$ & & & \\
\hline \multicolumn{6}{|c|}{ Apgar score } \\
\hline$<7$ & 4 & 9.8 & 25 & 0.390 & $0.131-1.160$ \\
\hline$\geq 7$ & 37 & 90.2 & $27 \quad 75$ & 1.203 & $0.972-1.490$ \\
\hline
\end{tabular}

Table 6

CTG findings and Apgar scores at 1 minute irrespective of the state of liquor

\begin{tabular}{lccccc}
\hline Characteristic & & Apgar $<7$ & Apgar $\geq 7$ & RR & $(95 \%$ CI $)$ \\
\hline \multirow{2}{*}{ Initial CTG } & Rate & & & & $0.139-1.009$ \\
& Normal & $9(13.6 \%)$ & $57(86.45 \%)$ & 0.375 & $0.859-2.143$ \\
& Abnormal & $4(36.4 \%)$ & $7(63.6 \%)$ & 1.357 & $0.424-3.084$ \\
& Decelerations & & & $0.792-1.195$ \\
Intra- & Normal & $6(18.2 \%)$ & $27(81.8 \%)$ & 1.143 & 0.973 \\
partum CTG & Abnormal & $7(15.9 \%)$ & $37(84.1 \%)$ & & $0.158-6.528$ \\
& Rate & & & & $0.687-1.448$ \\
& Normal & $12(16.9 \%)$ & $59(83.1 \%)$ & 1.014 & 0.997 \\
& Abnormal & $1(16.7 \%)$ & $5(83.3 \%)$ & & $0.115-1.083$ \\
& Decelerations & & & 0.127 & $0.085-1083$ \\
\hline
\end{tabular}


The indications for Caesarean delivery in the meconium group were non reassuring foetal status nine $(64.3 \%)$, cephalopelvic disproportion two $(14.3 \%)$, and malposition three $(21.4 \%)$ while in the clear liquor group non reassuring foetal status two $(28.6 \%)$, cephalopelvic disproportion four $(57.1 \%)$, and malposition one (14.3\%) (Table 7).

Table 7

Indications for Caesarean section

\begin{tabular}{lcccc}
\hline & Clear liquor & \multicolumn{2}{c}{$\begin{array}{c}\text { Meconium } \\
\text { stained liquor }\end{array}$} \\
& No. $(\%)$ & \multicolumn{2}{c}{ No. $(\%)$} \\
\hline NRFS & 2 & 28.6 & 9 & 64.3 \\
CPD & 4 & 57.1 & 2 & 14.3 \\
Malposition & 1 & 14.3 & 3 & 21.4 \\
\hline
\end{tabular}

One neonate was admitted with meconium aspiration syndromeand was hospitalised for morethan 48 hours and one mother who was from the meconium group was diagnosed with puerperal sepsis.

\section{DISCUSSION}

Variable decelerations were the most common abnormal foetal heart rate patterns observed at admission and also intrapartum in both groups. A possible explanation could be the resulting oligohydramnios after amniotomy with subsequent cord compression. Moderate or severe variable decelerations in the first stage of labour may be a sign of oligohydramnios and thus may be associated with a significant increase in the Caesarean delivery rate for foetal distress and with Apgar scores of $<7$ at 1 minute $(6,7)$. Patterns that predict foetal acidosis are severe variable decelerations and late decelerations. Our results did not completely support these observations since the Apgar scores in both groups were not different.

In the initial CTG, risk of having suspicious and pathologic CTG patterns was increased in the meconium stained liquor group compared with the clear liquor group. This is in agreement with several studies in which meconium-stained amniotic fluid was found to be a statistically significant factor that affected the occurrence of abnormal FHR tracings. Krebs et al (7) reported that foetuses with meconiumstained amniotic fluid exhibit abnormal foetal heart rate (FHR) patterns significantly more often than foetuses without meconium in their amniotic fluid (7). This trend was also observed in the intrapartum CTG whereby the risk of having a pathologic CTG with meconium stain was increased.

Significant percentage of suspicious pathology was seen in the clear liquor group in the initial CTG tracing. Pathologic pattern was present in intrapartum
CTG of women with clear liquor. The only sinusoidal pattern encountered was in the meconium stained liquor group. The presence of clear amniotic fluid, even in late labour, is an unreliable sign of foetal well-being. This questions a key component of active management of labour; the use of early amniotomy to detect meconium to make decisions regarding electronic foetal monitoring. It also suggests that the presence of clear amniotic fluid should not influence management where the cardiotocogram is not reassuring (2).

Meconium staining of liquor was significantly associated with Caesarean section delivery. Meconium-stained amniotic fluid has been shown to be a statistically significant factor that affects the occurrence of abnormal FHR tracings in several studies which may in turn prompt an urgent or emergency delivery on the basis of concern for foetal well being.

Only one neonate was admitted with meconium aspiration syndrome. This is in agreement with the studies, which confirm rarity of meconium aspiration syndrome. Virtually all foetuses exposed to meconium are born in good condition. This lack of specificity of meconium as marker of "impending asphyxia" accentuates the fragility of the cause and effect concept. Meconium aspiration syndrome, the major hazard attributed to meconium-stained amniotic fluid is, in part, a foetal environmental hazard when acidemia supervenes. It is hypothesized that the pathophysiology of meconium aspiration syndrome includes, butisnot limited to, foetal hypercarbia, which stimulates foetal respiration leading to intrauterine aspiration of meconium into the alveoli, and lung parenchymal damage secondary to acidemia-induced alveolar cell damage in the presence of meconium. Therefore meconium in the amniotic fluid may be a foetal environmental hazard when acidemia supervenes in the presence of meconium rather than solely a marker of preexisting foetal compromise leading to the release of meconium (8).

Apgar score of $<7$ was more likely if the initial base line rate was abnormal irrespective of the state of liquor. This was in agreement with Mahomed et al (3) that FHR abnormality was associated with adverse outcome than meconium staining. Elsewhere, Samo et al (6) found that an abnormal initial FHR tracing seems to be associated with the subsequent development of ominous FHR patterns and increased foetal morbidity, particularly when more than one abnormality is present on the initial tracing.

Only one woman who was from the meconium group was diagnosed with puerperal sepsis. Several mechanisms have been proposed for meconiumassociated puerperal infections, which include alteration in the antibacterial properties of amniotic fluid and enhanced bacterial growth. Additionally, impaired hostimmune response through theinhibition 
of phagocytosis and neutrophil oxidative burst by meconium was reported by Clark and Duff (9).

The use of oxytocin has been considered as a risk factor for meconium passage and worsening of foetal stress due to uterine hypercontractility. However in our study, $52.8 \%$ of patients in the meconium stained liquor group were augmented with oxytocin. Cardozo and Pearce (10) found that oxytocin administration did not increase the need for Caesarean delivery for foetal distress.

The parturients with clear liquor had a longer mean duration of labour (11.44 hours compared with 9.92 hours in the meconium group) though this was not statistically significant $(\mathrm{p}=0.07)$. The presence of meconium may increase physician anxiety, resulting in lower threshold for intervention and increased risk of operative delivery thus lessening the duration of labour.

In conclusion, variable decelerations and severe variable decelerations were the most common abnormal foetal heart rate patterns observed in both groups.

Women with clear liquor may have suspicious and pathologic CTG patterns though the risk for these outcomes was increased in the meconium stained liquor group.

There was no significant difference in the Apgar scores in both groups of parturients. Meconium staining of liquor was significantly associated with Caesarean section delivery and the commonest indication was non reassuring foetal status.

The parturients with clear liquor had statistically significant higher rates of augmentation of labour by oxytocin and they also had longer mean duration of labour. Oxytocin can still be used in mothers with meconium stained liquor as long as the foetal status is reassuring.

\section{ACKNOWLEDGEMENTS}

To Dr. Y. Patel for reviewing the CTG tracings, P. Osir who did data entry and analysis with great enthusiasm and Dr. K. Lubano for his constructive criticism of this work.
To all the women who came under our care, through them a lot of knowledge and experience was gained.

\section{REFERENCES}

1. Wiswell, T.E. and Bent, R.C. Meconium staining and the MAS. Paediatrics. Clin. North Am. 1993; 40: 955.

2. Greenwood, C., Lalchandani, S., Mac Quillan, K. et al. Meconium passed in labour. How reassuring is clear amniotic fluid. Obstet. Gynecol 2003; 102: 89.

3. Mahomed, K., Nyoni, R. and Masona, D. Meconium staining of the liquor in a low-risk population. Paediatr. Perinat. Epidemiol. 1994; 8: 292-300.

4. Klufio, C.A., Amoa, A.B., Kariwiga, G. and Rageau, O. Acase-control study of meconium staining of amniotic fluid in labour at Port Moresby General Hospital to determine associated risk factors and perinatal outcome. P. N. G. Med. J. 1996; 39: 297 - 309.

5. RCOG. The use of electronic foetal monitoring: The use and interpretation of cardiotocography in intrapartum foetal surveillance; Evidence-based Clinical Guideline Number 8, 2004. RCOG, London.

6. Sarno, A.P.Jr, Phelan, J.P. and Ahn, M.O. Relationship of early intrapartum foetal heart rate patterns to subsequent patterns and foetal outcome. J. Reprod. Med. 1990; 35: 239-242.

7. Krebs, H.B., Petres, R.E., Dunn, L.J., Jordan, H.V. and Segreti, A. Intra-partum foetal heart rate monitoring: III. Association of meconium with abnormal foetal heart rate patterns. Am. J. Obstet. Gynecol. 1980; 137: 936-943.

8. Urbaniak, K.J., McCowan, L.M. and Townend, K.M. Risk factors for meconium aspiration syndrome. Aust. N. Z. J. Obstet. Gynecol. 1996; 36: 401-406.

9. Clark, P. and Duff, P. Inhibition of neutrophil oxidative burst and phagocytosis by meconium. Obstet Gynecol. 1995; 173: 1301-1305.

10. Cardozo, L. and Pearce, J.M. Oxytocin in active-phase abnormalities of labour: a randomized study. Obstet. Gynecol. 1990; 75: 152-157. 